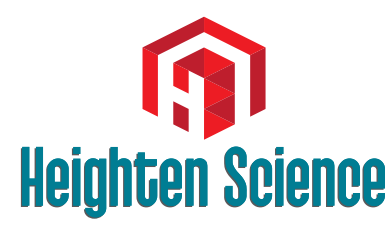

P U B L I C I T I O N S Corporation
Review Article

\section{Mental health promotion program in the workplace with focus on transport}

\author{
Olaf Jensen ${ }^{1-3 *}$, Fereshteh Baygi ${ }^{1}$, George Charalambous ${ }^{3,4}$, \\ Agnes Flores ${ }^{5,6}$, Lise Hedegaard Laursen ${ }^{7}$, David Lucas ${ }^{8}$ and \\ Debbie Andrioti ${ }^{1}$ \\ ${ }^{1}$ Centre of Maritime Health and Society, University of Southern Denmark, Esbjerg, Denmark \\ ${ }^{2}$ Faculty of Health Sciences, University of Panama, Panama City, Panama \\ ${ }^{3}$ Frederick University, Nicosia, Cyprus \\ ${ }^{4}$ Hippokration Hospital, Athens, Greece \\ ${ }^{5}$ Caja Seguro Social, Vacamonte, Panama \\ ${ }^{6}$ Metropolitan University of Education, Science and Technology, Panama \\ 'Independent Consultant \\ ${ }^{8}$ Université de Bretagne Occidentale, France
}

*Address for Correspondence: Olaf Jensen, Centre of Maritime Health and Society, Institute of Public Health, University of Southern Denmark, Esbjerg, Denmark, Tel:+50767417008; Email: ocj@health.sdu.dk

Submitted: 12 October 2018

Approved: 28 January 2019

Published: 29 January 2019

Copyright: @ 2019 Jensen 0, et al. This is an open access article distributed under the Creative Commons Attribution License, which permits unrestricted use, distribution, and reproduction in any medium, provided the original work is properly cited

Check for updates

\section{Abstract}

Five key sectors of transport have been selected as the target groups: seafarers, truck drivers, dockworkers, rail workers and airline workers. Transport workers often operate under stressful working conditions, long-work hours, lack of good sleep, healthy diet and physical exercises that contribute to fatigue, impaired well-being, mental ill-health, stress and chronic diseases. The hypothesis is that good mental health workplace culture depends on good education, staffing and management.

Objectives: To create, implement and evaluate a research based mental health culture promotion program

Determinate existing researches and training programs,

To study the knowledge, skills and needs for specific training in diferent age-groups

Create and implement effective and relevant training,

Produce training materials and scientific evidence available for ship owners, students and workers and to develop proposals for new mental health policies, legislations and regulations

Methods: Multidisciplinary training and research methodology with quantitative and qualitative research methods will be used. Validated mental health culture promotion methods with new programs for the specific sectors.
Expected impact
- $\quad$ Significant less sickness absence and suicides
- Benefit for the workers' health including benefit for the company economy.
- Policies developed for improved mental health culture based on the research.
- The training programs are ready to be continued at the end of the project.

\section{Introduction}

According to the European Commission, in most of the European countries, absence from work and early withdrawal from work due to mental problems have increased in recent years [1]. Mental health and problems such as depression anxiety and stress no present substantial financial costs for employers and employees as well as not seeing your edge loss for society as a whole [2]. Estimates at EU level say that it is direct 
health costs and thighs and losing productivity is more than 450 billion $€$ per year [3]. The society is aware that mental health is a growing problem that needs attention and systematic prevention. Unfortunately, public health care systems are far too focused on treatment of mental illness and prevention, for example in terms of stress management courses, psycho-therapy and minor tranquilizers is far too narrow. What is needed is an integrated multiphase primary prevention of mental illness and reduced welfare with focus on the workplaces [4]. The initiative from the EU Commission is aware that we should aim to strengthen the primary prevention and not let all means go to secondary prevention when the disease is progressive with clear and irreversible symptoms. Then it's often too late to do something efficiently. The EU Commission wants us to develop integrated preventive measures on workplaces so that severe illnesses and absenteeism from work as well as suicide are effectively prevented.

Transport activity over the borders, EU cornerstone, being a major contributor to the economy and a competitive force in business where it is crucial to have wellfunctioning workers [5,6]. Mental health challenges are well-known in the workplaces but there is a gap of knowledge and lack of systematic mental health promotion in the transport sector [7].

Five key sectors of transport have been selected as the target groups: seafarers, truck drivers, dockworkers, rail workers and airline workers. The scarce research show that the transport workers often operate under stressful working conditions, long-work hours, lack of good sleep, healthy diet and physical exercises, that contribute to fatigue, impaired well-being, mental ill-health, stress and chronic diseases. For all transport workers and sectors, well-being, mental health and fatigue are relevant subjects. Fatigue is considered as an important maritime safety and mental health problem [8]. The youngest are more burdened by stress, especially because of the lack of good social relationships, physical fatigue and lack of control [9]. A French survey with 74 seafarers on oceanographic vessels studied stress using the Karasek demandcontrol-model [10]. Of all respondents, $17 \%$ was at the low end of the decision level in the model of Karasek et al., and regarded as an expression of high stress risk. There was $33 \%$ with mental stress in the overall health tests. A particular risk factor among officers is a backlog of administrative work while in port, which creates difficulty in organizing work efficiently [11].

In the flight attendant populations, perceived poor health has been shown in the literature to be related to mortality, high job strain, and early retirement, and psychological distress is associated with work absence. The occupational illnesses that affect dock workers include mental disorders; among which depressive episodes were identified as the most frequent [12]. Pathological symptoms comprise irritability, sad mood, loss of interest and pleasure in daily activities, which can enhance feelings of fatigue, concentration difficulties and sleep disorders [13].

Truck drivers are at increased risk for depression when compared to the general population [14]. There is growing recognition of the importance of establishing mental healthcare services in the workplace because of the sharply increasing number of applications for workers' compensation due to suicides from overwork. In one study, $17 \%$ of truck drivers expressed suicidal thoughts, indicating that it is necessary to conduct follow-up surveys of the mental conditions of truck drivers in order to put in place the appropriate mental health prevention measures $[15,16]$.

\section{Hypotheses}

1. Mental wellbeing at work and in the training centres is related to mental health climate and the working conditions including organizational factors.

2. Mental health promotion intervention will result in mental health wellbeing, decreasing sick leave and suicide in the intervention centres. 
3. Also, diet, physical activity and personal drug abuse is related to mental health wellbeing.

4. Mental health promotion intervention will result in less absence from work due to mental health disease, less suicides and better economy for the companies.

5. The intervention cohorts have less injuries and near-misses than the controls.

6. Good vocational training centres produce the best students with less disease and turnaround.

\section{Objectives}

Our major objectives are to create, implement and evaluate a research based mental health culture promotion program, to determinate existing researches and training programs, to study the knowledge, skills and needs for specific training among the youngest workers in order to create and implement effective and relevant training, to produce training materials and scientific evidence available for ship owners, students and workers and to develop proposals for new mental health policies, legislations and regulations.

But also to determinate relationship between risk factors and mental health wellbeing, to study the knowledge, skills and needs for specific training among the youngest workers in order to create and implement effective and relevant training, the scope, the severity and the root causes of the mental health problems in the training centres, at work and in the company administrative units. We need to Focus on the students and the youngest workers' needs for training and work organizing being aware of the gender perspectives and to inspire the students to create supporting social private network via e.g. What Sapp closed groups (non-stigmatising social media).

\section{Methods and Materials}

\section{Study groups}

The target groups are the seafarers, truck drivers, dockworkers, rail workers and flight employees with focus on the training centres, the youngest workers and the companies' own administrations. The intervention programs will be specific for each of the target groups.

The plan is to include a total of 1-2 vocational school centre, 1-2 companies and samples of the members of the unions in each of the participating countries. The project will include in all 12-16 vocational school centres (half of them are control schools) and 10-12 transport companies in all. In each of the countries 1-2 universities, 1-2 occupational medical clinics and 1-2 help acute mental health centres. The concept is adapted from the WHO strategic methods for mental health culture promotion in concerted action with the informed participants who accept to complete their roles integrated with the other actors (Table 1). The process concept adapts to the international recognized method to plan and complete the improvement of the mental health climate in four steps:

1. Start with the "diagnostic" questionnaire based surveys and personal interviews of the mental health climate and needs in each of the partners own organization.

2. Followed by "diagnostic" questionnaire baseline surveys and interviews about the mental health conditions/climate for students in the vocational training centres.

3. Followed by concerted preventive actions with information and training. Main focus will be on the students at the vocational training centres and the employees in the partners' own administrative organisations.

4. Evaluation of the impact of the interventions by use of questionnaires, inspections, and interviews. 


\begin{tabular}{|c|c|}
\hline $\begin{array}{l}\text { Common tasks for all partners: } \\
\text { Universities, } \\
\text { NGOs acute help } \\
\text { Occupational Med clinics } \\
\text { Unions } \\
\text { Owners organisations, } \\
\text { Training centres } \\
\text { Occupational health services } \\
\text { Workers state authorities }\end{array}$ & 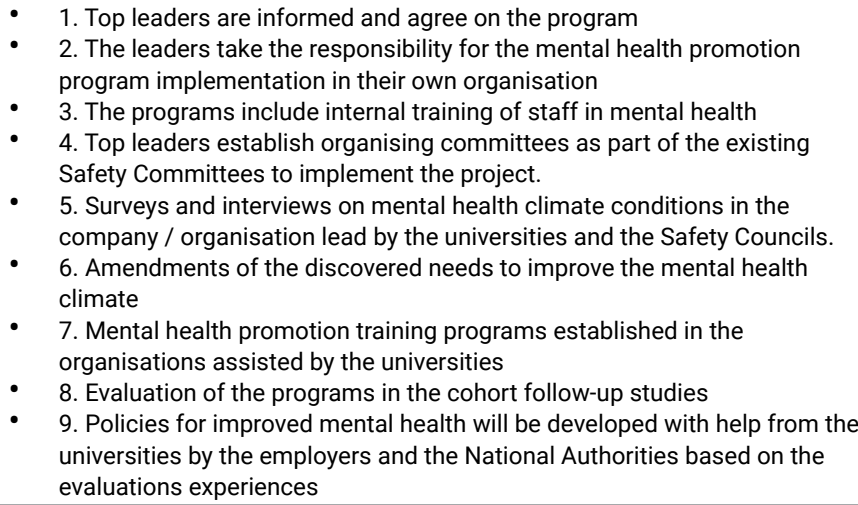 \\
\hline \multirow[t]{2}{*}{ Universities } & $\begin{array}{l}\text { The participating university departments will perform an extensive } \\
\text { research plan with monitoring-and information systems, starting with the } \\
\text { analysis of the mental health climate conditions in the shareholders own } \\
\text { organisations. }\end{array}$ \\
\hline & $\begin{array}{l}\text { Universities together with the partners prepare training in mental health } \\
\text { prevention and help with the amendments and follow-up of the effects }\end{array}$ \\
\hline NGOs acute mental help & - Provision of acute mental help and social care established and monitored \\
\hline Occupational Med clinics & - Provision of help to return to work by agreement with Occup. Med. clinics \\
\hline Unions & $\begin{array}{l}\text { The union members participate in the questionnaire surveys and } \\
\text { interviews to identify the mental health risks and complaints at the work } \\
\text { places }\end{array}$ \\
\hline Owners organisations & $\begin{array}{l}\text { - Study of the mental health climate and follow up of the changes after } \\
\text { implementation of amendments }\end{array}$ \\
\hline \multirow[t]{6}{*}{ Vocational training centres } & $\begin{array}{l}\text { 1) Mental health promotion programs are implemted in the vocational } \\
\text { training centres assisted by the universities + other relevant institutions }\end{array}$ \\
\hline & $\begin{array}{l}\text { 2) Concerted actions for prevention, training and information with the } \\
\text { main focus on the youngest workers are implemented at the vocational } \\
\text { training centres }\end{array}$ \\
\hline & $\begin{array}{l}\text { - 3) Followed by questionnaire studies of the risk factors among the } \\
\text { students }\end{array}$ \\
\hline & $\begin{array}{l}\text { 4) A mental health promotion program to be established by using the } \\
\text { competencies in the training institutions and effective solutions from } \\
\text { other institutions }\end{array}$ \\
\hline & $\begin{array}{l}\text { 5) Evaluations by mail contacts of interventions and amendments in the } \\
\text { cohorts }\end{array}$ \\
\hline & $\begin{array}{l}\text { 6) Inspire and teach the students how to have strong family and social } \\
\text { support in private networks via e.g. Whatsapp (not Instagram and similar } \\
\text { potential stigmatising social media) }\end{array}$ \\
\hline $\begin{array}{l}\text { Occupational health services } \\
\text { and National Occupational } \\
\text { Authorities }\end{array}$ & $\begin{array}{l}\text { - Occupational health services assist in preventing mental ill-health } \\
\text { improving work environment (e.g. communication, clear goals) by: } \\
\text { - } \quad \text { further training and learning opportunities } \\
\text { - } \quad \text { remomote health e.g. diet and physical activities } \\
\text { rehabitation and preventing substance abuse }\end{array}$ \\
\hline
\end{tabular}

\section{Methodology}

The project will use a multidisciplinary approach, consisting of social sciences and the humanities according to the WHO recommendations and guidelines: Mental Health Action Plan 2013 - 2020 and mental health promotion in the workplace 2013 - 2020, including $[17,18]$ :

1. Mental health promotion programs will be established by the top management of the vocational training centres.

2. Provision of acute mental help and social care to be established.

3. Provision of a mental health promotion program will use the competencies in the existing training institutions.

4. Execution of an extensive plan for research, monitoring, information and training on the mental health climate in the partners' own organizations.

\section{Inclusion criteria}

A basic requirement for participation is that the top management of the training 
centres agree to establish organising committees within the existing safety committees. Their task will be to plan and complete their designated tasks of the project.

The mental health promotion groups in the training centres will establish mental health promotion programs, including teaching modules in mental health promotion. Agreement with the acute mental help centres and the local occupational health clinics for help to return to the workplace will be established.

The need for acute psychological assistance is expected in cases where an employee has been exposed to an emergency incident at work. An acute incident is defined by the following:

Serious accidental incident, violence or threats of violence.

Assistance from the local mental health acute helping centres will be included in the project. The network of helpers can be reached by telephone and text messages in the participating countries. The Social Networks have established hotlines to be reached $24 / 7$ by all who needs help. Experiences of mental or physical violence, abuse, longer-term stress, whether the burden is work-related or a combination of family life that can lead to psychological problems.

We also included the formation of school based private network via e.g. social media in closed groups. Recommendations will be made to avoid Instagram and similar potential stigmatizing social media.

\section{Research methodology}

The research methodology will be multidisciplinary, including quantitative (epidemiology) and qualitative, social science research methods. The advanced scientific method of controlled intervention trials will be applied in the vocational training centres with baseline study and up to 4 years' follow up of the impact of the program. Advanced statistical methods will be applied in the analyses comparing before and after and between the control- and the intervention schools.

For review studies of the scientific literature on mental health at the workplace, mental health diseases and suicide, the method is collecting and analyzing several epidemiological studies together to strengthen the proof or evidence. The principles come from evidence-based medicine [19-21]. The reviews include health register based studies with suicide data and hospitalization data from transport workers compared with other workers. Review studies of the economic impact of mental health disease in the specific transport sectors will be included.

Baseline studies in the partners administrative centres, questionnaire and qualitative study design types will be used to study the distribution of the wellbeing mental health threats and the etiological related school- and workplace risk factors. The collaborating partners' own organizations include: vocational school centres, owner administration departments, unions and university departments

The safety councils in the partners' administrative centres will lead the surveys and interviews among the employees in the administrative centres and the following training and series of information and working group sessions. The safety organizations are in charge to establish the intervention training, amendments and control of implementation (Table 2).

Sending out the questionnaires to the union members by mail will include information links with videos, podcasts and written information (Table 3).

In the vocational training centre, methods for interventions are that they should be done in terms of training, information and group work at the training centres and Bruch- 
up sessions, In terms of private non-stigmatizing social networks. The interventions will be done as controlled experiments with intervention groups (I-groups) and matched for age and gender control groups (C-groups). The I- and the C-groups will be from different countries not to disseminate information to the C-groups and also to distribute the burden of work equally, Tables 4,5. The intervention and the control groups are surveyed at the same time with the same methods without knowing anything of each other. Qualitative and quantitative methods in random samples of the target groups will be applied. Different epidemiological and qualitative interview methods will be applied in random samples of the control and the intervention groups and compared in the analysis. The person time for the epidemiological measures include working hours, days or number of persons registered by the training centres.

Skilled scientists in the "Research - Work Package" will take care to produce high quality research in all phases of the descriptive-, etiological- and intervention protocols. All possible errors, e.g. related to the ethics, the size of the studies, methods for data collection and data analysis will be foreseen and amended in the detailed protocols and amended in good time. Pooling of data from different countries to obtain sufficient statistical material can be realized because the same indicators are used in all participating countries.

\section{Didactics}

The problem-based learning methods will be used in the group work. The students learn the methods, how to identify and give proposals of how to solve the mental health problems. This type of learning process will empower the students to develop useful skills for their future practice by searching and analyzing scientific documents besides the existing guidelines. The aim is to enhance critical appraisal, skills in literature retrieval and evidence-based health that encourages continuous learning after the school in a team environment in small groups.

\begin{tabular}{|c|c|c|c|c|c|c|}
\hline \multicolumn{2}{|c|}{ Table 2: Example of follow up with questionnaires and training in the partners administrative centres } \\
\hline Administrative centres cohorts & 2019 & 2020 & 2022 & 2024 & 2026 \\
\hline Questionnaires and interview & Baseline & $1^{\text {st }}$ repeat & $2^{\text {nd }}$ repeat & $3^{\text {rd }}$ repeat & Last repeat \\
\hline Follow-up in health registers & $\mathrm{x}$ & $\mathrm{x}$ & $\mathrm{x}$ & $\mathrm{x}$ & $\mathrm{x}$ \\
\hline
\end{tabular}

Table 3: Example of follow up with questionnaires and training for the union member cohorts $\mathrm{s}$ in the 4 industries

\begin{tabular}{|c|c|c|c|c|c|c|}
\hline & 2019 & 2020 & 2022 & 2024 & 2026 \\
\hline Union member cohorts & & & & & \\
\hline Questionnaires and interview & Baseline & $1^{\text {st }}$ repeat & $2^{\text {nd }}$ repeat & $3^{\text {rd }}$ repeat & Last repeat \\
\hline Follow-up in health registers & $\mathrm{x}$ & $\mathrm{x}$ & $\mathrm{x}$ & $\mathrm{x}$ & $\mathrm{x}$ \\
\hline
\end{tabular}

Table 4: Example of distribution of the intervention- and the control school cohorts in the countries.

\begin{tabular}{|c|c|c|}
\hline & Intervention cohorts & Control cohorts \\
\hline SHIPPING & Denmark & Germany \\
\hline DOCK WORKERS & France & Poland \\
\hline TRUCKERS & Italy & Greece \\
\hline AIRLINE PERSONNEL & Spain & France \\
\hline RAIL WORKERS & UK & USA \\
\hline
\end{tabular}

Table 5: Example of the follow up with questionnaires, interviews and health registers

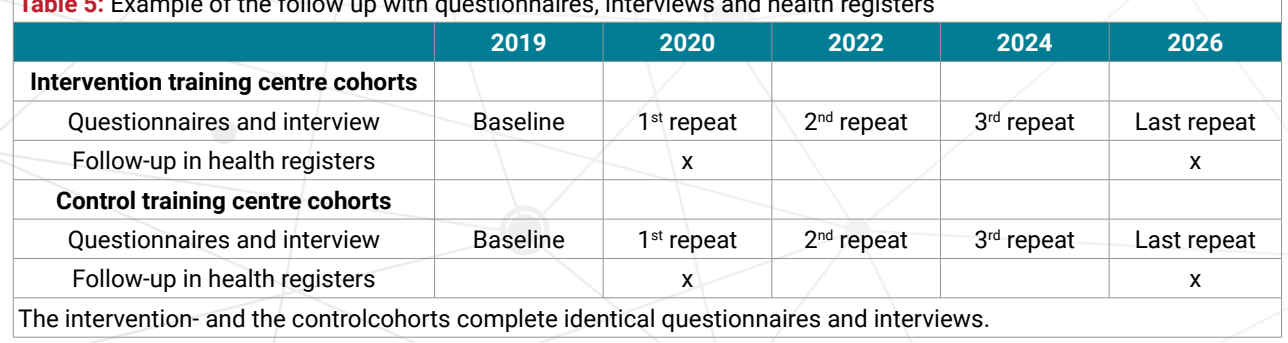


The students' working groups will select a specific scientific or practical project from a list and complete this under supervision from the teachers. The projects can be completed at distance except for some few classes with obligatory presence in the beginning, the middle and the end of the courses. The results will be available public and some of the projects will be used in the training.

The effect of the intervention will be evaluated by comparing the impact in the intervention groups with the control groups by objective and subjective indicators.

Objective indicators include:

- Register of absence from work due to mental health problems

- Hospitalizations due to mental health diseases

- Suicide and intention to suicide

- Change of job and industry

- Use of prescribed psychiatric medication

- Registration of harassment and violence in the workplace and the training centres

- Other relevant indicators

The subjective indicators include:

- Self-registered harassment and violence

- Questionnaires completed on the mental health climate

- Other relevant indicators

For the part of science

- The needed knowledge will be obtained from start as the baseline, diagnostic research to be followed up during the project by using different research methodologies: ethological and descriptive (epidemiological) quantitative studies, literature reviews and intervention studies using control groups in parallel with the intervention groups.

- Literature studies on suicide, risk factors and intervention studies in mental health.

- Literature reviews of vocational school materials to be used in similar settings.

- Literature reviews on workplace mental health economy.

- Studies on mental health risk factors and reasons for leaving the industries

- Gab analysis of the needs for vocational training in mental health.

The established intervention and control group school cohorts will be followed-up by using different research methods on the abovementioned indicators with logistic regression analysis. National health registers will be used to document the burden of suicide and hospitalizations of all causes in each of the transport sectors compared with each other and with other industrial branches. The questionnaire based followup studies, every 2 years up to 4 years, will be combined with interview studies. The results will be published in the partners own information letters, in international scientific journals and presented at national and international conferences. The results with experiences will be used in the training- and information activities. In the research 
and training activities where relevant, the gender dimension will be taken into account in the project's content. Our aim is to strengthen the collective empowerment to win better conditions for women transport workers. Key issues include access to decent pay, jobs and advancements and the right to work free from violence. In every Work Packet, the leaders will be prompted to screen their work to see how the gender perspective can be actualized in the project.

\section{Discussion}

The ambition is to produce high quality research and effective training programs that can be used by the partners in the future to improve the working environment. The interventions will be wider than on board the transport vessels, all teachers in the vocational schools, employees in the organizations and state authorities will be trained to support a sound occupational and mental health environment in the industry. The transport workers often face more difficult working conditions than other employees. The mental health is affected by the living conditions and long working hours contribute to stress, anxiety and loneliness that again can lead to depression and suicide. The aims are to improve the transport workers' mental health and their health in general. Our target population will be the seafarers, truck drivers, dockworkers, rail workers and the aviation workers. The youngest transport workers belong to the most vulnerable groups, so the program will focus on the youngest but all age groups will be included.

During and after the project a continuous monitoring of the mental health indicators and the related risk factors will be performed in samples by the companies and the training centres. This knowledge is used for the integration of mental and physical health culture promotion in the continuing education and brush-up courses for the employees in the years to come.

Monitoring of the risk factors for mental health will also include the risk factors for other types of non-communicative diseases like diabetes, hypertension and cardiovascular diseases. The prevention of the co-morbidities related to mental health, like nutrition, physical activity and drug abuse is included in the prevention plans. We expect that this program to have impact in different and various fields.

\section{Compliance with the requirements of the call}

The needed knowledge will be obtained from the extensive research part of the project. The research is divided in the following phases:

1. Diagnostic start phase to identify the type and severity of mental health problems in the industry.

2. Follow-up up with annual surveys and interviews.

3. The research will be multidisciplinary with different research methods: literature review studies based on health registers to document the burden of suicide and hospitalisations in each of the transport sectors compared with each other and with other industrial branches.

4. Inferences will be drawn by integration of the qualitative and quantitative studies in triangulation so the final results depend on the combined findings.

5. The follow-up studies of the student groups (cohorts) established at the training centres are combined with interview studies.

6. The research includes intervention training centres and control centres. The students in the intervention centres will have the specific mental health promotion program while the control centres have the ordinary training. The control and the intervention schools will be in different countries to avoid bias. 
7. The training programs will address diagnosed challenges in mental health risks in the workplace under the "diagnostic" research phase and the follow-up phases in the cohorts.

8. Different types of training materials will be developed based on existing training materials and supplemented with the results from the research by the universities in collaboration with the partners.

9. The schools will be inspired to continue with their effective mental health programs they already have implemented. This project will contribute by adding scientific based evaluation of the programs and advice of how to improve the programs and point out which parts of the existing programs are the most effective.

10. When the project ends, the intervention programs will be available for the employers and organisations for their use. Instructions will be given on how to continue the program with continuous monitoring of the risk factors and the health conditions as part of the training of new employees.

11. Co-morbidities in mental and physical health will be addressed

12. Monitoring of the risk factors for mental health will include the risk factors for other types of non-communicative diseases like diabetes, hypertension and cardiovascular diseases.

13. The stigma attached to mental ill health will be considered as well as other important social and cultural factors in the questionnaire based and sociological based studies. The formation of school based social private network via the social media.

\section{Expected health impact}

1. Significant improved mental health and reduced sickness absence is expected.

2. The number of tele-medical consultations and repatriations (for seafarers) due to mental health problems and the number of long-time absence from work will be reduced.

3. Suicide, hospitalizations and work absence will be reduced and documented by health register cohort studies.

4. Reports from Radio Medical for seafarers will be used to document the reduced number of calls, repatriations and deviations of the ships due to mental health complaints.

5. Students from the training training centres will be enrolled in study cohorts to be followed with questionnaires every second year in the first 4 years.

\section{Expected financial impact}

1. The responsible partners for the Work Packages will ensure that the project will be a benefit not only for the good working environment for the workers but also for the company economy.

2. The positive impact on productivity and economic results of workplaces will be of benefit for the communities by reducing the social and health system costs.

3. The developed new policies based on the research will further improve the financial impact for the community and for the private industries.

\section{Expected policy impact}

1. A policy for improved mental health will be developed based on the experiences and the research. 
2. The research results and the experiences from the training courses (interviews with the students) will provide the needed knowledge as the basis to formulate policies as proposals for the politicians to get proper mental health conditions for the workers.

3. One of the Work Packets is dedicated to analysis of the needs and to develop proposals for new relevant mental health policies, legislation and regulations on EU- and national levels

4. The policies will include vocational school training with mental health promotion modules together with advices for diet and physical activity to be integrated and obligatory in the vocational education centres.

\section{Impact for drugs and alcohol control}

1. A negative working environment may lead to physical and mental health problems, harmful use of substances or alcohol and drugs, absenteeism and lost productivity.

2. The frequency and the aetiology behind of the use of drugs and alcohol is analyzed in order to focus on prevention on the most relevant risk factors (22).

\section{Expected scope and impact of the trainings}

1. Vocational school trainees will be trained every year in mental health promotion and later all transport vocational school centres will be trained and inspired for life-long learning.

2. Module books with instructions on how to use problem-based learning will be developed for use in the professional vocational school centres.

3. Surveys will be executed among thevocational students and thetransportworkers' union members on knowledge and skills to create preventive environments for prevention on mental health and other NCDs (Non-Communicable Diseases, especially obesity, diabetes and cardiovascular diseases).

\section{References}

1. St-Arnaud L, Bourbonnais R, Saint-Jean M, Rhéaume J. Determinants of return-to-work among employees absent due to mental health problems. Relat Ind Relat. 2007; 62: 690-713. Ref.: https://goo.gl/91TkhB

2. Horizon 2020 Work Programme 2018-2020 8. Health, demographic change and wellbeing [Internet] EU-Commission; Available from: Horizon 2020 Work Programme 2018-2020 8. Health, demographic change and wellbeing. 2018; Ref.: https://goo.gl/1ervr4

3. International Labour Office, Labour Administration LI and OS and HB. Workplace stress: a collective challenge. Geneva: ILO; 2016.

4. Cano GM, Wooley S. Perspectives for public policies in mental health. Sick or well-a citizen first: The (Ex-) User/Survivor Voice in Democracy. Inf Psychiatr. 2016; 92: 723-730. Ref.: https://goo.gl/WVrZQ4

5. CSCMP, Goldsby TJ, lyengar D, Rao S. The Critical Role of Transportation in Business and the Economy. 2014. Ref.: https://goo.gl/iJT3gW

6. Freight transport activity increase in comparison to GDP growth in EU 27, 1990-2030. European Environment Agency. 2009; Ref.: https://goo.gl/mhqos8

7. Towards a Sustainable European Transport System: Investing in Clean and Innovative Solutions I Public Policy Exchange. 2018; Ref.: https://goo.gl/b1ggWh

8. Allen $P$, Wadsworth $E$, Smith A. Seafarers' fatigue: a review of the recent literature. Int Marit Health. 2008; 59: 81-92. Ref.: https://goo.gl/iQobxX

9. Jezewska M, Leszczyńska I, Jaremin B. Work-related stress at sea self estimation by maritime students and officers. Int Marit Health. 2006; 57: 66-75. Ref.: https://goo.gl/UH9vtC 
10. Lodde $B$, Jegaden $D$, Lucas $D$, Feraud $M$, Eusen $Y$, et al. Stress in seamen and non seamen employed by the same company. Int Marit Health. 2008; 59: 53-60. Ref.: https://goo.gl/FE6oeS

11. Oldenburg $M$, Jensen $H-J$, Latza $U$, Baur $X$. Seafaring stressors aboard merchant and passenger ships. Int J Public Health. 2009; 54: 96-105. Ref.: https://goo.gl/CqDc2C

12. Cezar-Vaz MR, de Almeida MCV, Bonow CA, Rocha LP, Borges AM, et al. Casual dock work: profile of diseases and injuries and perception of influence on health. Int J Environ Res Public Health. 2014; 11: 2077-2091. Ref.: https://goo.gl/jnLgff

13. Almeida MCV de, Cezar-Vaz MR, Almeida MCV de, Cezar-Vaz MR. Scientific evidence of dockworker illness to nursing clinical reasoning. Rev Esc Enferm USP. 2016; 50: 346-354. Ref.: https://goo.gl/MKdF4b

14. da Silva-Júnior FP, de Pinho RSN, de Mello MT, de Bruin VMS, de Bruin PFC. Risk factors for depression in truck drivers. Soc Psychiatry Psychiatr Epidemiol. 2009; 44: 125-129. Ref.: https://goo.gl/2DJKiL

15. Chen GX, Sieber WK, Lincoln JE, Birdsey J, Hitchcock EM, et al. NIOSH national survey of long-haul truck drivers: Injury and safety. Accid Anal Prev. 2015; 85: 66-72. Ref.: https://goo.gl/rnVPm5

16. Kaneko SY. Mental health survey of truck drivers. Nihon Eiseigaku Zasshi Jpn J Hyg. 2014; 69: 199204. Ref.: https://goo.gl/76tP6J

17. WHO | Mental health action plan 2013 - 2020. WHO. 2018; Ref.: https://goo.gl/35jyaT

18. WHO | Mental health in the workplace [Internet]. WHO. 2018; Ref.: https://goo.gl/oVKojo

19. Mani K, Provident I, Eckel E. Evidence-based ergonomics education: Promoting risk factor awareness among office computer workers. Work Read Mass. 2016; 55: 913-922. Ref.: https://goo.gl/RBMNnh

20. Porru S, Calza S, Arici C. Prevention of occupational injuries: Evidence for effective good practices in foundries. J Safety Res. 2017; 60: 53-69. Ref.: https://goo.gl/BDqNhd

21. Kim KI, Jung HK, Kim CO, Kim SK, Cho HH, et al. Evidence-based guidelines for fall prevention in Korea. Korean J Intern Med. 2017; 32: 199-210. Ref.: https://goo.gl/BRkYJE

22. Substance Abuse and Mental Health Issues: Dealing with Drug or Alcohol Addiction and Co-Occurring Mental Health Problems. 2018; Ref.: https://goo.gl/w1SZSL 